\title{
Subjective vs objective description of judgment policy
}

$D A V I D \quad A, \quad S U M M E R S, J, \quad D A L E$ TALIAFERRO, and DONNA J. FLETCHER, University of Kansas, Lawrence, Kans. 66044

Subjective descriptions of judgment policy were compared with the descriptions afforded by an objective regression model. It was found that (1) Ss reported using more cues than were indicated by the model, (2) the subjective weights reproduced Ss' judgments with substantially less accuracy than did the objective regression weights, and (3) Ss communicated the function (linear vs nonlinear) characterizing their policies with better-than-chance accuracy.

Numerous investigators have found that human judgment policies can be simulated by using multiple-regression techniques. In particular, multiple-regression models have been found to be useful in such areas as clinical inference (e.g., Hoffman, 1960; Hammond, Hursch, \& Todd, 1964), human learning (e.g., Peterson, Hammond, \& Summers, 1965), personnel selection (Naylor \& Wherry, 1965), foreign-policy beliefs (Summers \& Stewart, 1968), and interpersonal conflict (e.g., Summers, Stewart, \& Oncken, 1968). In studies such as these, Ss are shown a series of multidimensional stimuli (e.g., profiles of job applicants) and are asked to make a judgment about each (e.g., regarding job suitability). Multiple-regression equations are then derived for each $S$, where the stimulus dimensions ("cues") serve as predictors for S's judgments. The resulting regression weights may then be used to infer which cues $S$ utilized when making his judgments and how these cues were utilized.

Despite the apparent usefulness of multiple-regression models, only limited attention has been given to the relationship between the subjective policy description provided by S's self-report and the objective description provided by the regression model. While it has been shown that S's subjective description of his cue utilization often departs from the account provided by the regression model (Hoffman, 1960; Oskamp, 1967), certain questions remain unanswered. Specifically, can Ss provide a description of their judgment policies that will reproduce their judgments at a substantial level of accuracy? Similarly, how accurately can Ss communicate the function (linear vs nonlinear) that characterizes their policies?

\section{METHOD AND PROCEDURE Judgment task}

The task involved judgments about the future socioeconomic growth of underdeveloped nations. Each nation to be judged varied simultaneously on four dimensions (cues), where these dimensions were represented by 10-point scales. Specifically, these dimensions were (1) amount of foreign investment in that country, (2) amount of government influence over private enterprise, (3) foreign aid received from the U.S., and (4) the number of socialist deputies, or representatives, in the nation's congress. The nations were generated by independently specifying a value from 1 to 10 on each scale; cue intercorrelations were therefore near zero $( \pm .08)$. A total of 175 hypothetical nations were generated for the task.

\section{Procedure}

One hundred and thirty-one University of Kansas undergraduates were instructed to make a judgment (on a 10-point scale) about the level of socioeconomic development each nation would achieve over the next 50 years. Following completion of the judgment task, Ss completed a posttask questionnaire, in which they were instructed to provide: (1) their subjective weights and (2) a verbal description of their policies. With regard to (1), $S$ was instructed to distribute 100 points among the four cue dimensions so as to reflect the weight assigned to each cue relative to the others. With regard to (2), S was instructed to write a description of his policy in sufficient detail to allow another person to reproduce his judgments.

\section{RESULTS AND DISCUSSION2 Objective vs Subjective Cue Utilization}

The objective cue utilization weights were obtained by regressing S's judgments on the four stimulus cues and then transforming the regression weights into relative weights (Hoffman, 1960) as follows: $R W_{i}=\left(r_{i} b_{i} / R^{2}\right)(100)$, where $b_{i}$ represents the regression coefficient for the $i^{\text {th }}$ cue, $r_{i}$ represents the correlation between S's judgments and that cue, and where $R^{2}$ denotes the squared multiple correlation between S's judgments and all four cues. As a result of this transformation, both the objective and subjective weights summed to 100 for each S.

As shown in Table 1, the subjective weights differed substantially from the weights derived from the regression analysis. Note that the subjective weights suggest that Ss depended more or less equally on all four cues. In contrast, the objective weights indicate that Ss utilized the foreign-investment dimension substantially more than the other dimensions and tended to ignore the socialist-deputies dimension.

Discrepancy indices were calculated for each $S$ in terms of both (1) the mean absolute difference between objective and subjective weights and (2) the square root of the mean squared difference between objective and subjective weights (referred to as "self-insight error" by Oskamp, 1967). With regard to (1), the absolute difference (averaged over the four cues) between the objective and subjective weights ranged from 2.5 to 35.0 . The mean absolute difference score was 17.4 , thus indicating that S's own estimate of the weight he assigned to each cue departed (on the average) approximately 17 units from the estimate provided by the regression model. With regard to (2), it was found that "self-insight error" ranged from 3.1 to 41.0 , with a mean of 20.4 . It should be noted that the "self-insight error" evidenced by these Ss was considerably greater than that found by Oskamp in his study of clinical judgment; i.e., when expressed in equivalent units, the mean self-insight error shown by his Ss was only 9.1. It is possible that the greater experience enjoyed by Oskamp's Ss in that particular judgment domain is at least partially responsible for this difference.

Finally, a sign test revealed that the number of cues Ss reported using was significantly greater than the number of cues objectively utilized $(z=4.77$, $\mathrm{p}<.001) .^{3}$ In this regard, 34 Ss $(26.4 \%)$ objectively utilized all four cues, $53 \mathrm{Ss}$ (41.1\%) utilized three cues, 33 Ss (25.6\%) utilized two cues, and 9 Ss $(6.9 \%)$ utilized only one cue. In contrast, 126 Ss (97.7\%) reported having utilized all four cues, while the remaining three Ss $(2.3 \%)$ reported having utilized three cues. In short, Ss tended to report their judgment policies as more complex than indicated by the regression model. This finding is consistent with results reported elsewhere (Oskamp, 1967).

Table 1

Mean Objective and Subjective Cue Weights

Stimulus Cues

\begin{tabular}{rrrr}
$\begin{array}{c}\text { Foreign } \\
\text { Invest- } \\
\text { ment }\end{array}$ & $\begin{array}{c}\text { Govern- } \\
\text { ment } \\
\text { Influence }\end{array}$ & $\begin{array}{c}\text { Foreign } \\
\text { Aid }\end{array}$ & $\begin{array}{r}\text { Socialist } \\
\text { Deputies }\end{array}$ \\
\hline 36.5 & 27.7 & 20.9 & 14.9 \\
27.3 & 27.6 & 24.5 & 20.7
\end{tabular}




\section{Objective vs Subjective} Accuracy

The correlations between S's actual judgments and the judgments predicted by the multiple-regression equation were generally high, i.e., the median $\mathrm{R}$ was .75 . In contrast, when the subjective weights reported by the $S s$ were substituted for the $b-o e f f i c i e n t s$ derived in the regression analysis, the median correlation between the actual judgments and the predicted judgments was .60. In short, when S's subjective weights were used to reproduce his judgments, the variance accounted for was approximately $20 \%$ less than that accounted for by the objective regression model.

\section{Function Form}

Inspection of $\mathrm{Ss}^{\prime}$ verbal descriptions revealed that $70 \mathrm{Ss}$ described their policies as nonlinear, i.e., they indicated that they used the cues in either a curvilinear or configural manner. The remaining $60 \mathrm{Ss}$ indicated that they used the cues in a simple linear manner. If the verbal descriptions provide an accurate account of the Ss' linear vs nonlinear cue utilization, the multiple $R$ between the four cues and S's judgments should be lower for the "nonlinear" Ss than for the "linear" Ss. Such was indeed the case. The median $R$ for the "nonlinear" Ss was .72, while the median $\mathrm{R}$ for the "linear" Ss was .79. Though this difference is not great, a Mann-Whitney $U$ test revealed that the two groups differed significantly $(z=2.64$, $\mathrm{p}<.01$ ).

It should be noted that the smaller multiple Rs associated with the Ss who reported nonlinear cue utilization could be the result of response inconsistency rather than actual nonlinearity. Hence, in order to assess nonlinear (i.e., curvilinear and/or configural) cue utilization, a 14-term regression equation including all possible squared and first-order interaction terms was applied to each S's responses. When the multiple Rs derived from this nonlinear analysis were compared with the multiple Rs previously derived from the linear analysis, it was found that the improvement in predictive accuracy was typically small, i.e., the median $\mathrm{R}$ derived from the nonlinear model was .81 , as compared with .75 for the linear model. Nevertheless, a small (but significant) difference was found between the "linear" and "nonlinear" Ss, i.e., the improvement in predictive accuracy afforded by the nonlinear model was greater $(t=3.41$, $\mathrm{p}<.01)$ for the "nonlinear" Ss $(.062)$ than for the "linear" Ss (.037). It should be pointed out, however, that previous studies have shown cross-validation Rs for nonlinear judgment models to be generally low. As a result, the superiority of the nonlinear model for the Ss who described their policy in nonlinear terms should be viewed with caution.

\section{SUMMARY AND CONCLUSIONS}

The results reported here support findings reported in other studies involving quite different judgment tasks. Specifically, Ss' subjective weights failed to reflect the differential cue weighting indicated by an objective analysis of $\mathrm{Ss}^{\prime}$ responses. Moreover, the Ss typically attributed greater complexity to their judgment policies than was warranted by the multiple-regression analysis, i.e., the number of cues Ss claim to have utilized was typically greater than was objectively the case. As a result, Ss' subjective weights reproduced their judgments less accurately than did the objective regression weights, i.e., the variance accounted for by the subjective weights was approximately $20 \%$ less than that accounted for by the multiple-regression model. Furthermore, while these Ss communicated (with better-than-chance accuracy) the linear or nonlinear function relating their judgments to the stimulus cues, the gain in predictive accuracy resulting from application of a nonlinear model to $\mathrm{Ss}$ who described themselves as nonlinear was quite small.

In conclusion, these results suggest that even in a relatively simple four-cue judgment task such as studied here, S's self-report of his judgment policy is of limited value in reproducing his judgments. Moreover, these results point to some of the problems that are likely to arise when two or more individuals attempt to communicate their judgment policies to each other. As shown here, neither S's quantitative estimates of his cue weighting nor his verbal description is likely to convey an accurate account of his policy. The consequences of this failure of self-report could well include misunderstanding, mistrust, and even conflict.

\section{REFERENCES}

HAMMOND, K. R., HURSCH, C., \& TODD, F. Analyzing the components of clinical inference. Psychological Review, 1964, 71, 438-456.

HOFFMAN, P. J. The paramorphic representation of clinical judgment. Psychological Bulletin, 1960.57, 116-131.

NAYLOR, J., \& WHERRY, R. The use of simulated stimuli and the "JAN" technique to capture and cluster the policies of raters. Journal of Educational \& Psychological Measurement, 1965, 25, 969-986.

OSKAMP, S. Clinical judgment from the MMPI: Simple or complex? Journal of Clinical Psychology, 1967, 23, 41 1-415.

PETERSON, C. R., HAMMOND, K. R., \& SUMMERS, D. A. Optimal cue weighting in multiple probability learning. Journal of Experimental Psychology, 1965, 70, 270-276.

SUMMERS, D. A., \& SEEWART. T. R. Regression models of foreign policy beliefs. Proceedings of the 76th Annual Convention of the American Psychological Association, 1968, 195-196.

SUMMERS, D. A., STEWART, T, R., \& ONCKEN, G. R. Interpersonal conflict in heterocultural dyads. International Journal of Psychology, 1968, 3, 191-196.

\section{NOTES}

1. This research was partially supported by a University of Kansas Biomedical Sciences Support Grant and by Advanced Research Project Agency Contract No. F44620-68-C-0081.

2. One $S$ provided unusable responses to the judgment task and was dropped from the study. Another $S$ provided unusable subjective weights and was not included in analyses involving those data.

3. The number of cues $S$ objectively utilized was based upon the number of b-coefficients that differed significantly from zero $(p<.01)$. 